\title{
UZH's Chem MusEum e-Learning Concept
}

\author{
Heidi C. Weber ${ }^{\star}$ and Marina Macrina
}

\begin{abstract}
The Chem MusEum of the University of Zurich is the latest project of the Chemical Institutes for living
\end{abstract} history in terms of an interactive online exhibition.

Keywords: Chemical Museum · e-Learning concept $\cdot$ History of Chemistry $\cdot$ UZH

\section{Introduction}

The Chemistry Institutes of the University of Zurich enjoy a rich chemical history and possess an enormous collection of historical instruments and chemical memorabilia to document significant milestones achieved through ground-breaking research done at UZH over the past 176 years. The UZH Chem MusEum presents an online interactive exhibit of this treasury accessible to a broad audience.

Chem MusEum will show, in an interactive way, the research at the Chemical Institutes from its beginnings up to the present day. The implementation will be realized with an Internet platform where we will present videos, interactive tools, and graphical 3D animations. The different sections will include an overview of the research groups from the foundation of the University in 1833 to the newest research results now published in our institutes, including the methods and measurement techniques from then and now. This online museum provides interesting and understandable insights into the chemistry and history of the generations of scientists, thereby providing inspiration to the current generation of students. Selected online experiments and well-documented descriptions will help students reflect on their current content of curriculum. The Chem MusEum provides an opportunity to delve

${ }^{\star}$ Correspondence: Dr. H. C. Weber Institute of Organic Chemistry

University of Zurich

Winterthurerstrasse 190

$\mathrm{CH}-8057$ Zurich

Tel.: +41446354229

E-mail: weberhe@oci.uzh.ch into the fascinating field of chemistry and its historical content, in a visual, interactive way.

The virtual tour will guide visitors through four exhibition halls: an online gallery of the principal scientists (History) with adjacent cinema, a unique collection of Chemistry archives (Historical Instruments), a more modern view of techniques of measurement (Modern Instruments), and an experimental lab (Experiments) with neighboring video room.

The Chem MusEum can be found on the Internet, at http://www.oci.uzh.ch/general/OCIMuseum/index.html

\section{History}

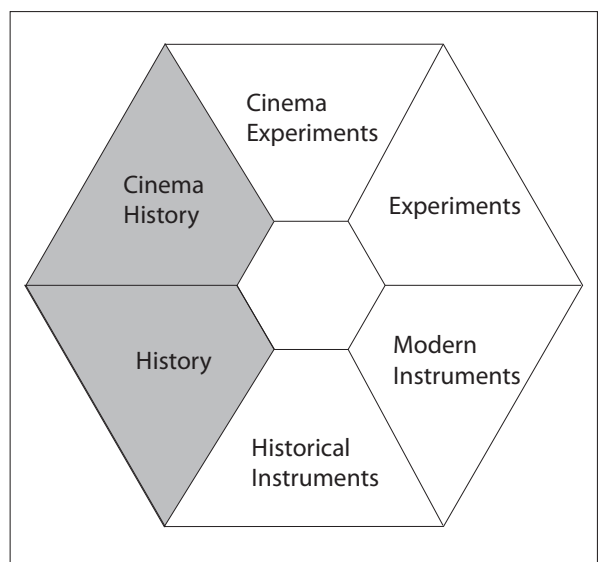

On April 29, 1833, the 'Universitas Turicensis' was founded. The University ceremoniously opened under the vice chancellor Lorenz Oken with 55 tutors and 161 students. It was the first university in Europe to be founded by the state rather than by a monarch or church. ${ }^{[1]}$ It was envisioned that the University of $\mathrm{Zu}$ rich should become a model for a Swiss National University, and signaled a social liberalism that created great prosperity and a high standard of living in Switzerland. Over the years, many great thinkers have taken creative refuge in Zurich. From the beginning of this movement, an important role has been given to chemistry.
A Chair for chemistry was established, together with a laboratory and a small annual budget for equipment. The first occupant of this Chair was a pharmacist, only 30 years old, Professor Carl Jacob Löwig. ${ }^{[2]}$ It is from this point our journey through the intellectual work spanning the last 176 years begins. An online gallery of the principal players in the Chemical Institutes will present the historical sights of the research groups as well as their discoveries.

Carl Jacob Löwig was an excellent lecturer, internationally known for his remarkable textbook on general chemistry. ${ }^{[3]}$ He first focused on the analysis of local mineral waters. For this work he received an honorary degree from the faculty of medicine in Bonn. Later, he turned to organic and physiological research problems. His discovery of cellulose in tunicates received wide attention. To his discoveries belongs the pioneering work in organo-main group chemistry of the preparation of triethyl stilbane and tetraethyl lead, once a common antiknocking agent in gasoline. Among elemental detectives, he was the co-discoverer of bromine. Löwig was also the tutor of Hans Heinrich Landolt, the founder of physical chemistry in Germany. ${ }^{[2,4]}$ Thus, from the very beginning, one sees that chemistry at UZH has been pursued broadly over a wide number of disciplines and with ramification to neighboring fields, such as medicine. The associated professors have always been generalists recruited internationally, and the earliest alumni were the founders of great movements in chemistry beyond the Swiss borders.

Following the chronology, the Professor Georg Städeler was recruited to a UZH position in chemistry in 1853 . When the Eidgenössische Polytechnische Schule, known as the ETH, opened its doors on October 15, 1855, Städeler also became a professor in theoretical chemistry there. He is known for a) his work on the amino acids, leucin and tyrosine, important in the detection of liver disease, b) his research on allantoin, an accompanying excretion with uric acid as end product of nucleic 

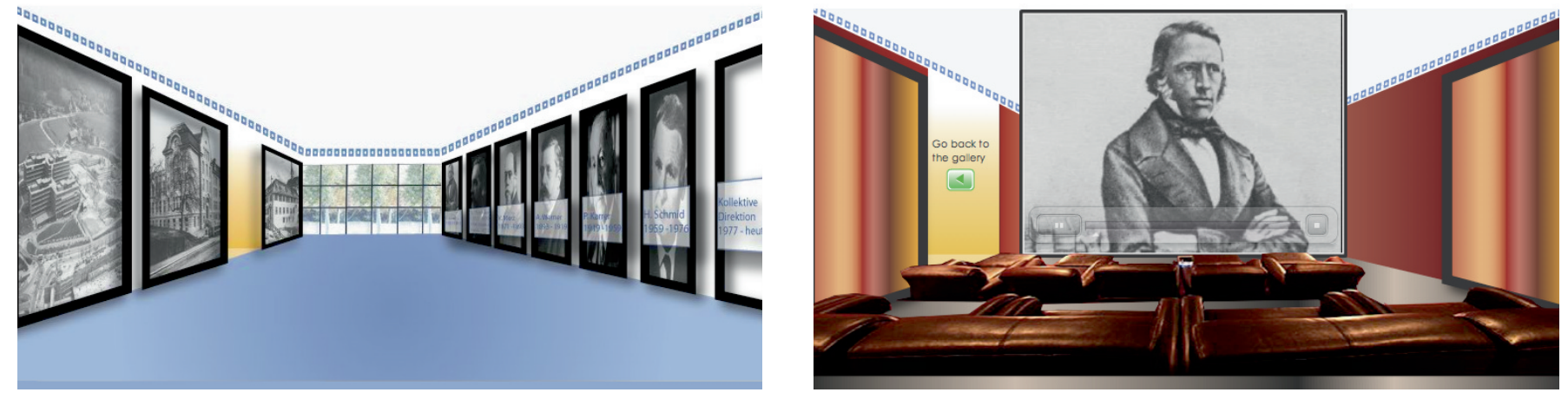

http://www.oci.uzh.ch/general/OCIMuseum/Geschichte.php

acid metabolism in mammals, and c) his work on creatine, an organic acid that helps to supply the muscles in vertebrates with energy. In addition, Städeler worked on chitin, a polysaccharide that occurs in mushrooms, mollusca, and articulata, and on fibroin, a type of protein excreted by silkworms for the production of silk. He determined the correct empirical formula of lactose, an important sugar in milk, and of xanthine, a purine base found in most human tissues and fluids as well in other organisms. He also synthesized pinacones from ketones by means of reductive coupling with active metal and protic acid. In autumn of 1870 , he left his post at UZH due to health problems. ${ }^{[2,4]}$

In April 1871, Städeler's famous student, Johannes Wislicenus, extended the work of his mentor, and became full professor at UZH, and eventually also became Städeler's successor at the ETH, continuing the double-professorship between UZH and ETH. Wislicenus founded the Chemische Harmonika in the 1860's, which since 1870 has been called the Zürcher Chemische Gesellschaft (Zurich Chemical Society). One of his scientific topics concentrated on expansion of Kekule's structural theory of organic molecules. Lactic acid played a central role in this pursuit of Wislicenus, and he determined its structure in 1873. Wislicenus left Zurich for the University of Wurzburg in 1872.[2,4]

Through the time period of the dual mandate of Städeler and Wislicenus, the laboratories at the University and the ETH did not always see eye-to-eye. The University of Zurich evaluated two candidates for the open position in chemistry, Victor Merz and Wilhem Weith. Victor Merz obtained his PhD under the supervision of Städeler during his habilitation years. However, due to a disagreement with Städeler, he switched to the group of Wislicenus, where he met Weith. As Merz and Weith complemented one another perfectly, both were chosen for the open UZH position. ${ }^{[2,4]}$

With Alfred Werner the 'Erziehungsdirektion' had chosen one of the most talented chemists of the last century. At the age of 27, Alfred Werner became successor of Victor Merz. He was gifted as a lecturer, often filling the lecture halls well past capacity. The conditions in the laboratories were intolerable, and the large number of students utilized every corner of the institute. The museum still has some statements of Werner's students, describing the environmental condition of their job in the old laboratories in Rämistrasse 45. The laboratories in the basement of the main building are described to be without ventilation and natural light, forcing students to work under artificial light even on sunny days. The students themselves named these laboratories the 'catacombs' because of this.

In 1909, the Institute of Chemistry moved to the new building on Rämistrasse 76. The new building was designed according to Alfred Werner's wishes. The old building plans are one of the treasures of our archives. One can see that, from Werner's office, he could directly access the small lecture hall, the laboratory, and the library, over small iron spiral staircases going down to the students' lab and going up to the preparation room of the old lecture hall.

Coming from organic chemistry, Alfred Werner evolved his research direction into inorganic chemistry, for which he is credited as the father of coordination chemistry. Werner was the first to propose a correct geometry for transition metal coordination complexes (the octahedral geometry), and he also observed many different isomers. He was the first to synthesize a full inorganic chiral compound. The chemical archive holds an enormous cache of Werner's original samples, preserved in sealed glass ampoules, many as pure as the day they were made. These can be viewed on the museum Internet site. In 1913, Alfred Werner was honored as the first Swiss chemist with the Nobel Prize as the founder of Coordination Chemistry, with the following citation: "in recognition of his work on the linkage of atoms in molecules by which he has thrown new light on earlier investigations and opened up new fields of research especially in inorganic chemistry". ${ }^{[2,5]}$

Despite his unparalleled success in inorganic chemistry, Werner's contribution to organic chemistry should not be underestimated. His work on aromatic compounds, for example phenathrene derivates, was highly respected and he was keenly interested in Kekule's theory on the structure of benzene.

Following the advice of Alfred Werner, Paul Karrer was appointed as his successor in 1920. It was the time after the First World War and the institute was nearly orphaned. In his early years as a director of the institute, Karrer focused on the systematic assembling of new instruments, and built up the new microanalysis laboratories as a service. In the beginning, Karrer focused his research on polysaccharides and polymeric carbohydrate structures, concentrating specifically on anthocyanines, water-soluble vacuolar pigments in plants. He was internationally known as a master of natural products. In 1931, Karrer was able to isolate vitamin $\mathrm{A}$ and determine its chemical structure. In 1935, he synthesized vitamin B2 (riboflavin), and in 1939 he isolated vitamin $\mathrm{K}$, analyzed flavine, which is the common name for a group of organic compounds based on pteridine, and worked on the structure elucidations of carotenoids. Later, Karrer concentrated his work on the curare alkaloids. Karrer's interests were always related to the biological activity of natural products. His research also had, in contrast to Alfred Werner, a large influence on the chemical industry. [2] For his work on carotenoids, flavinoids and vitamins $\mathrm{A}$ and $\mathrm{B}_{2}$, Paul 
Karrer was honored with the Nobel Prize in 1937. ${ }^{[6]}$ Numerous artifacts of the Karrer era fill the archive, making for a wealth of online viewing material. The collections of Karrer's samples are also still available in our museum and can be viewed online.

In the old days, there was no separation in 'physical, inorganic, and organic chemistry'. Already under Alfred Werner a new Department of Physical Chemistry was established, and Victor Henri, a famous scientist of molecular spectroscopy and photochemistry, was chosen as the first Professor of Physical Chemistry in 1920. In 1931, with the approval of Paul Karrer, the Institute of Physical and Organic Chemistry became two separate entities, and Hans von Halban, who established the independent Institute of Physical Chemistry, became the first director. Recently, the Physical Chemistry Institute celebrated this happening on its $75^{\text {th }}$ anniversary. The successor of von Halban, Klaus Clusius, an international and well-known established scientist, was appointed in 1947. Under the directorship of Heinrich Labhart, the successor of Prof. Clusius after his sudden death in 1963, two more faculty positions were established. Georges Wagnière, an expert on semi-empirical calculations of the molecular structure and spectroscopic properties of molecules, joined the institute in 1965. Hanns Fischer, an expert in free radical chemistry, joined the institute in 1969. In 1979 Robert Huber became successor of Heinrich Labhart, after Labhart's unexpected death in 1977. Two years later, Karl Lendi and Henning Paul joined the institute as 'Privatdozenten,' and later as 'Titularprofessoren'. Prof. Lendi's research focused in the area of irreversible quantum dynamics in open systems, including interaction with an environment. Henning Paul focused on spin chemistry, specifically the question of how chemical reactions are influenced by magnetic fields using time-resolved ESR methods. Marco Nonella joined the team as 'Bundesprofessor' of computational science from 1992 to 1996 . Currrently, the physical chemistry institutes comprises Stefan Seeger, Peter Hamm and Jürg Hutter. ${ }^{[7]}$ The historical artifacts in this area of chemistry are present in the online museum.

When Karrer retired in 1959, independent Organic and Inorganic Chemistry Institutes were established. The historical collections of the Chemical Institutes were placed under the auspices of the Institute of Organic Chemistry, OCI. Up until that time, Karrer was considered to be expert in both areas, albeit weighted heavily towards organic chemistry. The record would indicate that an establishment of a more egalitarian administrative structure earlier on might have led to a more collegial growth of the Chemical Institutes, without the need for the formal splintering into institutes. Indeed, Gerold Schwarzenbach, and Paul Pfeiffer before him, more closely represented the growing area of inorganic chemistry founded by Werner, than did Karrer. Both left UZH to pursue major careers in inorganic chemistry. Had there been greater parallel growth in the chemistry faculty, UZH might have been a leading house across an even broader spectrum of chemistry.

Ernst Schumacher, a former student of Klaus Clusius, was the first director of the Institute of Inorganic Chemistry in 1959. He pointed the research focus in the institute more towards problems in physical-inorganic chemistry. In 1964 he left the University, and in 1966 his successor became Hans R. Oswald. Two years later a new chair was established and was occupied by Helmut Werner, an organometallic chemist building bridges between the classical disciplines of organic and inorganic chemistry. John Ammeter joined the institute from 1978 to 1985 as Associate Professor. John Günter joined the institute as Assistant Professor in 1981, became Associate Professor in 1990, and retired in 1999. In 1988, Heinz Berke became full Professor, and subsequently took over as Chairman of the Institute of Inorganic Chemistry in 1991. Berke's major research field concerned organometallic chemistry mainly related to the exploration and exploitation of physical properties of organometallic compounds as molecular materials and metal catalysis of organic reactions. Roger Alberto, the successor of Hans R. Oswald in 1999, is working in the fields of coordination and organometallic transition metal compounds and their application to radiopharmacy. In 2003 Roland Sigel and in 2007 Greta Patzke entered the institute as Assistant Professors. Most recently, in 2008, Eva Freisinger joined the institute as an Assistant Professor. ${ }^{[8]}$

Hans Schmid became the first Director of the Institute of Organic Chemistry. He studied and finished his dissertation in chemistry at the Chemical Institute at the University of Vienna. Hans Schmid reflected his personality in many fields of organic chemistry. The first of his research topics was natural substances. He continued Karrer's work on curare, but focused more on isolation and structure problems than on the organism itself. In 1949, a research visit in Berkeley in the group of Professor Melvin Calvin, introduced Schmid to the ${ }^{14} \mathrm{C}$ technique. It was the time after the Second World War and information exchange, and therefore such visits became quite productive. The ${ }^{14} \mathrm{C}$ technique became later essential for his mechanistic research, where he concentrated on the exact determination of the process of molecular transformation in the living cell. One of his famous topics was the research on the Spanish fly, which some of his researchers collected in Sicily and brought back to raise in the laboratory. Cantharidin, a terpenoid, which became later important for biochemical research was extracted and its structure elucidated. ${ }^{[2]}$

After Hans Schmid's sudden death in 1976, a collective Directorship was established with an alternate rotated leader position. In 1978, the new chemistry buildings at the Irchel Campus were inaugurated. In the years that followed, several independent research groups were established. Max Viscontini (biogenesis research studies in microorganisms), André Dreiding (Dreiding models) Conrad Eugster (phytochemistry), Wolfgang von Philipsborn (nuclear magnetic resonance) Manfred Hesse (mass spectrometry), and in 1981 Andrea Vasella (sugar chemistry).

Max Viscontini became the first Director of the collective directorship, followed by André Dreiding, Conrad Eugster, Wolfgang von Philipsborn, Manfred Hesse and Andrea Vasella. Due to some inauspicious decisions from the university leadership the collective directorship formally declined to three Professors in 2000. In 1989, only two of the three retired chairs, Max Viscontini, André Dreiding and Conrad Eugster, were newly occupied by HansJürgen Hansen and John Robinson.

In 1993, Andrea Vasella responded to a call at the ETH. In 1997, Wolfgang von Philipsborn retired, in 2002 Manfred Hesse, and in 2004 Hans-Jürgen Hansen. To bring a fresh new start to the Institute of Organic Chemistry, a special committee was formed to seek out the best candidates, resulting in the recruitments of Jay Siegel in 2003, and Kim Baldridge in 2004. The subsequent years re-established the institute's international leading reputation in both research and teaching. ${ }^{[3]}$

\section{Unique Collections in the Chemistry Archive}

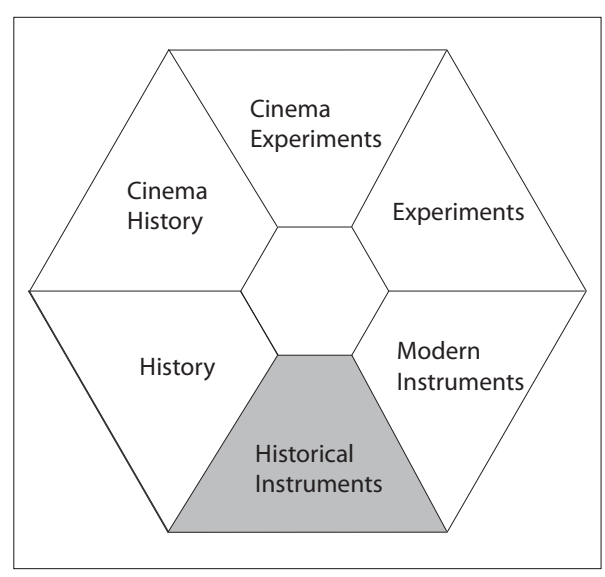

The enormous collection of curiosities stored in the Chemistry Institutes archive 
gives the visitor the opportunity to emerge into the long-term history of the Chemistry Institutes

Highlights from the earlier days include the well-preserved microbalances, the oldest one in our archive is from 1870, and the laboratory burner from Johann Wolfgang Doebereiner, one of the first burners from 1829. A unique collection of preserved samples builds another highlight of the archive. An important piece of evidence of Professor Werner's work on phenanthrene derivatives is still present in our archive. His laboratory notebook contains all the preparations of these different salts. The sealed tubes with phenanthrene and its derivatives were synthesized by Werner's students. An enormous number of alkaloid samples from Paul Karrer, and later from Hans Schmid and their groups, are stored in the archive. In the period from 1918 to 1959, 76 prepared sealed test tubes containing alkaloid and curare derivates were synthesized. One of a kind is the Kugelrohr-distillation apparatus fabricated by Emil Kohler, the mechanic in Professor Karrer's group under guidance of Hans Schmid, who learned this technique in Vienna. The fraction collectors were also very useful instruments in Hans Schmid's group. Professor Hansen remembers one in particular that was made by Dr. Hans Häsli, that was so robust that it was called the 'Military Version'. A very complicated but very important apparatus was the countercurrent chromotography system, used for separation of alkaloid mixtures. This apparatus, which was very complicated to use but cutting edge for the time, is a testament to the frontier research in the area of chromotography science, pioneered by the Karrer-Schmid research groups. Remarkable time records from the establishment of the NMR services include the water-cooled magnets of the earlier NMR magnets, established also in the Institute of Organic Chemistry.

These and many more treasuries will be made accessible to a broad audience through the museum website. Entering the collection by way of the chemistry hall in the online museum, the examples of the ar- chive collection can be chosen according to different search criteria stored in a database structure. A short description to the historic pieces will be shown to the visitor.

\section{Modern Measurement Techniques}

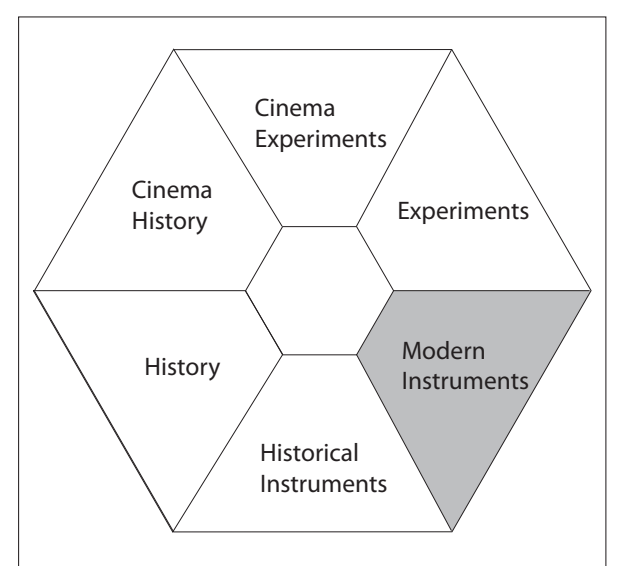

The chemistry institutes are supported with a wide range of state-of-the-art technologies, which results in a variety of highlevel sub-disciplines of research. As a result, an increasing number of international young scientists come to study chemistry at our institutes. To facilitate first-year students, the Chem MusEum provides an easily accessible guide to the different measurement techniques, as well as an overview of the main laboratory equipment they may be exposed to, as well as the historical background of the equipment.

In addition to the basic instruments from the laboratory of the first-year chemistry, such as chemical balances, coolers, heaters, columns, spectrometers, gas chromatography systems, distillation systems, and many more, students will be provided an overview of all of the instruments offered in the chemical services. The Chemistry Institutes have a long tradition of having a well-established infrastructure, offered for chemical research. Already under Professor Karrer, the first service laboratory for micro-analysis was established. At the suggestion of Hans Schmid, the first IR spectrometer was purchased in 1955.
When Hans Schmid became Director, not only were the elemental analysis services expanded, but a new NMR service was founded. Manfred Hesse brought the mass spectrometry service to the Institute of Organic Chemistry. With the move in 1978 to the Irchel Campus, the X-ray crystallography service was established. The computational hands-on classroom was initiated by Roland Kunz, and later extended by Kim Baldridge to include a Grid Competence Center. All of these infrastructure services have been expanded to the highest research standards and are available to internal and external scientists. The Chemistry Institutes now offer infrastructure services on nuclear magnetic resonance spectroscopy, mass spectrometry, X-ray crystallography, absorption/emission spectroscopy, microanalysis, and computational chemistry. ${ }^{[9]}$ The instrumentation of these services is open to the classes taken by the students.

\section{No Chemistry without Experiments}

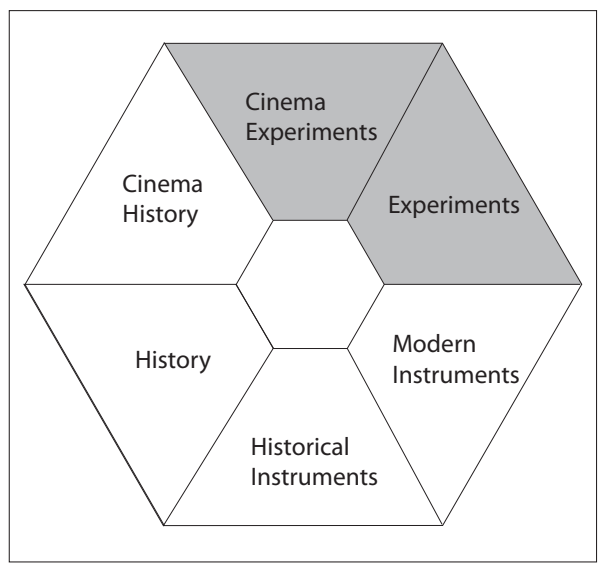

The Chem MusEum will present a large number of exciting experiments, which will enable students as well as all other interested parties, to review and obtain a basic knowledge in experimental procedures. The various experiments are meant to align with the various lectures offered to first-year students. Each of the experiments will have an introduction of the basic theory involved, a description

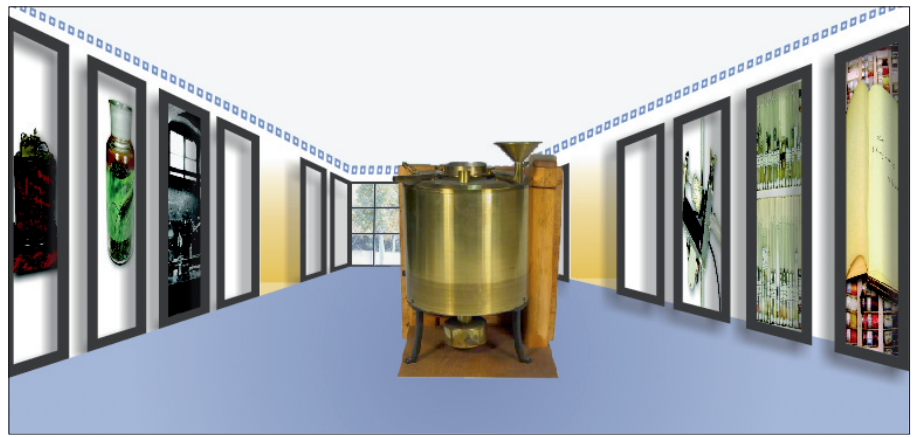

http://www.oci.uzh.ch/general/OCIMuseum/InstrumenteHistorisch.php

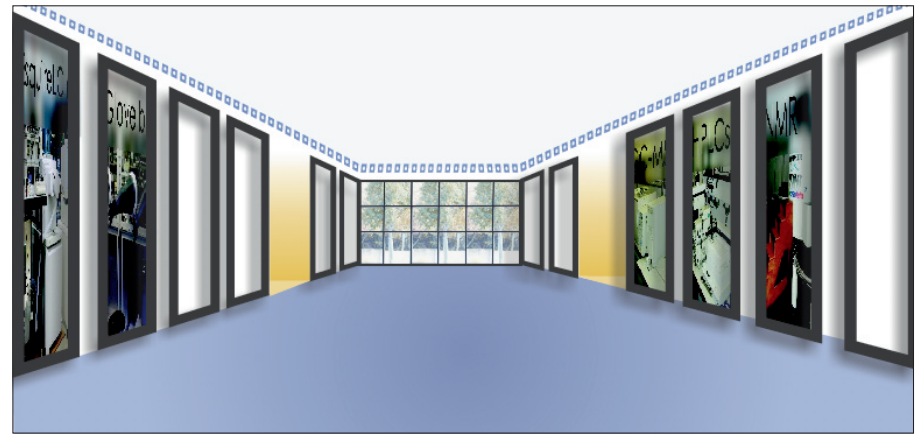

http://www.oci.uzh.ch/general/OCIMuseum/InstrumenteModern.php 


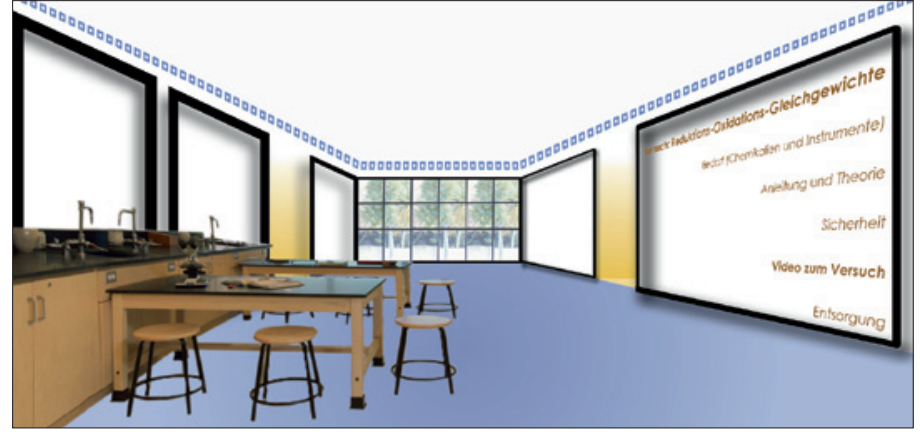

http://www.oci.uzh.ch/ general/OCIMuseum/ Experimente.php

of equipment used in that experiment, information concerning the chemicals and safety, a video tutorial or a computer simulation, and additional information concerning disposal safety.

The 3D animations are intended to provide additional understanding and insight into the molecules involved in the experiments, including the formation, the bonding, and the structure, in a concrete way. Such simulations highlight some of the important characteristics of the experiments.

The online chemical experiments laboratory provides an additional benefit, particularly for experiments that are very complex, expensive, or even dangerous to carry out in real time. However, the online experiments are not meant to completely replace the work in the laboratory, but are intended as a supplement, and to better prepare the student for the real experiments. Additional exercises to the experiments, as well as an online forum will also be available.

\section{Outlook}

The Chem MusEum is an IIL (initiative interactive learning) project, with the aim of providing a supplement to how the process of learning takes place in the real classroom situation. The museum will be realized, particularly in the experimental component, in close collaboration with the lecturers of the first-year students. Addi- tionally, due to the fact that all information content will be stored in a database that will be updated regularly by the various group contributors themselves, the latest changes can be integrated into the museum in an automatic way.

The Chem MusEum will be implemented in different phases and will be fully operational in August 2011.

\section{Acknowledgements}

The author gratefully acknowledges Profs Kim K. Baldridge and Jay S. Siegel for their valuable contribution and insight into this articles. The author also is thankful to Dr. Christa Werner for carefully reading this piece, to Steve Ellington for photography and film digitization, and to Armin Guggisberg for many helpful suggestions.

Received: August 19, 2009

[1] http://www.uzh.ch/about/portrait/history.html

[2] C. Eugster, Chimia 2008, 62, 75.

[3] J. S. Siegel, Chimia 2008, 62, 68

[4] '75 Jahre chemischer Forschung an der Universität Zürich', Festschrift zur Eröffnung des neuen Chemischen Instituts verfasst von den Studierenden der Chemie.

[5] http://nobelprize.org/nobel_prizes/chemistry/ laureates/1913/

[6] http://nobelprize.org/nobel_prizes/chemistry/ laureates/1937/karrer-bio.html

[7] J. R. Huber, Chimia 2008, 62, 103.

[8] R. Alberto, G. R. Patzke, R. K. O. Sigel, H. G. Berke, Chimia 2006, 62, 111.

[9] J. S. Siegel, H. Heimgartner, Chimia 2008, 62, 114. 